\title{
A CASE OF SEVERE HYPERCALCAEMIA OF INFANCY WITH AN ACCOUNT OF THE NEUROPATHOLOGICAL FINDINGS
}

\author{
BY \\ L. CROME and PETER E. SYLVESTER \\ From the Fountain Hospital, Tooting, London
}

(RECEIVED FOR PUBLICATION APRIL 22, 1960)

Hypercalcaemia of infancy has been divided into severe and simple or benign forms, each with distinct clinical pictures. However, Joseph and Parrott (1958) considered that the two forms were different degrees of severity of the same disease. Forfar, Tompsett and Forshall (1959) thought that the severe form, which tends to be recognized later in infancy, was the result of delay in diagnosis.

The severe form, which according to Fellers and Schwartz (1958) is 14 times less common than the simple form, was first described by Fanconi, Girardet, Schlesinger, Butler and Black (1952). Amongst its multiple symptoms and signs are dwarfism, mental retardation, persistent hypercalcaemia, hypercholesterolaemia, osteosclerosis and evidence of renal disturbance with albuminuria and nitrogen retention. The prognosis is poor. By contrast, the simple form first described by Lightwood (1952) is unassociated with mental deficiency and osteosclerosis and has a good prognosis.

Several workers have described the visceral changes, particularly renal, in severe hypercalcaemia, but neuropathological findings have not been hitherto reported. The object of this communication is to record a case which came to autopsy and had a full pathological examination.

\section{Case History}

The patient, the first born of healthy parents, the mother 18 and the father 37 years of age, with no family history of mental or neurological illness, was delivered normally after a labour lasting 44 hours. The pregnancy was normal. He weighed $9 \mathrm{lb}$. $6 \mathrm{oz}$. $(4,220 \mathrm{~g}$.) at birth and his head circumference of $14 \frac{1}{2}$ in. $(36 \cdot 8 \mathrm{~cm}$.) was of normal size. He had a capillary-cavernous 'strawberry' naevus on the outer side of the right elbow $\frac{7}{8}$ in. $\left(2 \cdot 2 \mathrm{~cm}\right.$.) in diameter and a similar lesion $\frac{5}{8}$ in. $(1.6 \mathrm{~cm}$.) in the left deltoid region.

At first he progressed normally but on the 3rd day he had a cyanotic attack and was given oxygen. Later the same day he had several tonic convulsions with opisthotonus and flexion of all limbs, each attack lasting about two minutes. Cerebrospinal fluid was clear and xanthochromic with a protein content of $300 \mathrm{mg}$. \% and a normal cell count.

He was weaned on to half-cream national dried milk at 17 days and changed gradually to full-cream milk at 12 weeks. One teaspoonful of cod liver oil was given daily. He was a slow feeder, often vomited and was constipated. These features persisted throughout life.

The cutaneous naevi increased in size up to the 4th month after which they became stationary. At this time his head circumference, $15 \frac{7}{8}$ in. $(40 \cdot 2 \mathrm{~cm}$.), was within normal limits. At 5 months his blood pressure was $124 / 76 \mathrm{~mm}$. $\mathrm{Hg}$ and radiography showed normal bone development and calcification of hands and feet. Convulsions, consisting of sudden jumps, stiffness of the arms and legs, and cyanosis continued. Although some measure of control was achieved by sedation he sometimes had several attacks a day. At 9 months he was considered to be mentally retarded, deaf and blind with optic atrophy.

While in hospital from 11 months to 2 years and 3 months weight gain was satisfactory in spite of feeding difficulties and intercurrent respiratory infections. The fontanelles closed normally but his head size increased very slowly and at 2 years the circumference was $16 \frac{3}{4}$ in. $(42.6 \mathrm{~cm}$.). His pupils did not react to light and he had slight nystagmus. The discs were small and pale but the retinae were normal. All limbs were hypertonic and the reflexes brisk. Plantar reflexes were extensor. The Mantoux 1/1,000 and toxoplasmin skin tests were negative. Marrow and blood counts were normal.

Many chemical investigations were carried out during the first 2 years of life. The blood urea was raised between 60 and $82 \mathrm{mg}$. \%. Calcium in the blood varied from 11.3 to $16.6 \mathrm{mg}$. \% (the diagnostic level given by Stapleton and Evans (1955) was $12.5 \mathrm{mg} . / 100 \mathrm{ml}$.). Blood phosphates were between 5.5 and $9.9 \mathrm{mg}$. \%; plasma protein $7 \cdot 0$ to $7 \cdot 3 \mathrm{mg}$. \%; serum cholesterol $293 \mathrm{mg}$. \%. The alkaline phosphatase in six estimations varied between 15.7 and 28.4 King Armstrong units/ $100 \mathrm{ml}$. but there was a seventh estimation in which it was 5.4 units $/ 100 \mathrm{ml}$. The $\mathrm{CO}_{2}$ combining power was $30.8 \mathrm{mEq}$./litre. The $\mathrm{I}^{131}$ excretion test was normal. 


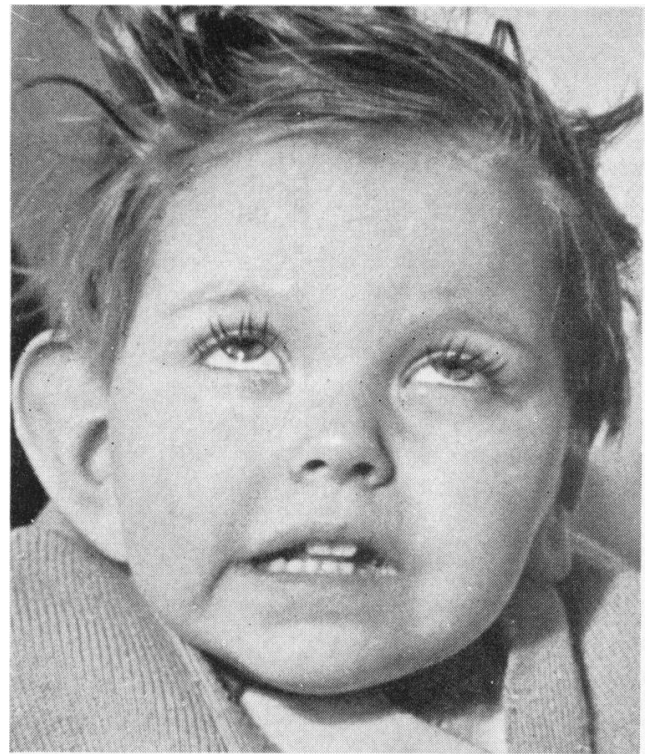

FIG. 1.-Rounded face with eyes set wide apart, epicanthic folds and large low-set ears.

Paper chromatography revealed a normal amino-acid urinary excretion. C.S.F. protein returned to normal towards the end of the first year.

He was admitted to the Fountain Hospital at the age of 2 years and 3 months when he was found to be an idiot behaving like a 2-month-old baby, requiring three-hourly bottle feeding. He could not talk, sit, stand, walk, nor even lift his head. He showed no apparent interest in his surroundings and rapport could not be established. His weight was $22 \mathrm{lb}$. and head circumference $16 \frac{3}{4}$ in. $(42.4 \mathrm{~cm}$.) (normal is $49.7 \mathrm{~cm}$.).

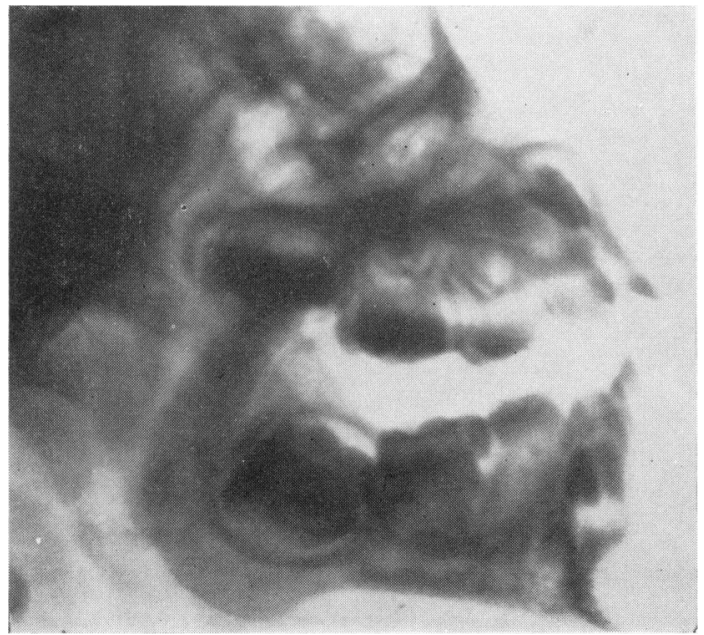

Fig. 2.-Two small foci of calcification in the first premolar.
His face was round with eyes set wide apart, epicanthic folds were present and the ears were large and low-set (Fig. 1). He lay in a curious 'frog' position, the legs abducted at the hips and maintained rigidly in a flexed position. There was spastic diplegia.

Two weeks after admission to the Fountain Hospital, he developed a pyrexial attack (103 to $105^{\circ} \mathrm{F}$.) with haemoconcentration and a leucocytosis of 20,000. Choreic movements of the face and limbs, head retraction and arching of the back occurred. Excitement and screaming attacks were frequently present and he often slept during the day and was sleepless at night. When asleep his movements ceased. The cause of his illness, which persisted intermittently till death seven months later, was obscure, in spite of many investigations. These excluded meningitis, middle-ear disease and other infections. A moderate degree of papillitis lasting about six weeks was noted. C.S.F. protein increased to $90 \mathrm{mg} . \%$ with a slight increase of globulin but other constituents were normal. Dr. Frank Elliott suggested that the cause of these symptoms and signs might be naevoid amentia with naevoid malformation at the base of the hypothalamus and pons, a diagnosis of some significance in view of subsequent findings. Radiography of the skull and spine at 2 years and 5 months revealed generalized osteosclerosis and two foci of calcification in the pulp of a deciduous premolar (Fig. 2).

He died from broncho-pneumonia at the age of 2 years and 10 months.

When the child was 10 months old the parents had a second infant, a girl, who developed normally and at 8 years was fit and well.

Pathological Findings. At necropsy performed on the day of death, the body was found to be well nourished. However, comparison with Coppoletta and Wolbach's (1933) tables of organ weights of infants and children revealed that his stature of $81 \mathrm{~cm}$. (normal $88 \mathrm{~cm}$.) was stunted and the weights of his heart, lungs, spleen, liver, kidneys and brain were all lighter than the average for his age. His head circumference was $42 \cdot 6 \mathrm{~cm}$. (normal $50.4 \mathrm{~cm}$. , S.D. $= \pm 1.35 \mathrm{~cm}$.). He was therefore microcephalic.

Foetal lobulation was present in both kidneys (left 35 g., normal 49 g.; right $30 \mathrm{~g}$., normal $48 \mathrm{~g}$.), each of which showed longitudinal yellowish streaking of the medulla. Atheromatous deposits encircled the commencement of the aorta. The heart was well formed.

The brain, symmetrical in shape and covered by clear leptomeninges, weighed $825 \mathrm{~g}$. (normal 1,140 g.). It was very soft at the time of removal and, with convolutional flattening, was considered to be oedematous. The olfactory and optic nerves appeared small but other cranial nerves were normal. Attached to the caudal part of the optic chiasma and anterior part of the tuber cinereum and chiasma and the hypophysis cerebri, was a soft grey nodule $4 \mathrm{~mm}$. in diameter (Fig. 3). Basal vessels were normal. There were no naked eye abnormalities of the spinal cord.

Histological Findings. Coronal sections of the frontal, temporal and occipital lobes, the basal ganglia, mid- 


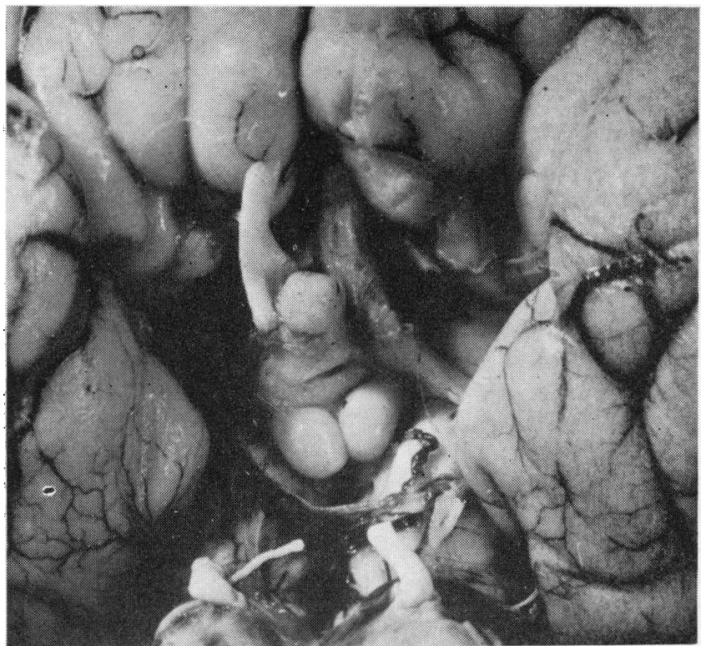

FIG. 3.-The small rounded infundibuloma arising from the floor of the third ventricle and anterior part of the hypophysis cerebri.

brain, pons, medulla, cerebellum, cervical, thoracic and lumbar cord were embedded in celloidin and sections stained by the usual neuropathological proceduresNissl, Heidenhain, H.V.G., Mallory's P.T.A.H. and
Holzer techniques. Paraffin embedding was carried out on the optic nerves, cortex and viscera and sections were stained by the H.V.G., H. and E., P.T.A.H., Glees Marsland and Loyez methods. Frozen sections of the cortex were used for Holzer, von Kossa and Scarlet R. methods.

The gyri were well formed but lamination within their grey matter was often indistinct and there was a generalized sparsity of nerve cells especially in layer III. Betz cells, looked for in many blocks, were absent from the motor cortex. The striate cortex could not be identified with certainty. Perigyral gliosis was increased in some areas, notably in the frontal, parietal and occipital lobes. The white matter was well medullated. However, it contained many ectopic nerve cells e.g. in the corona radiata there were five times more nerve cells than in an equivalent area of the brain of a mature newborn infant and 30 times more cells than in the brain of an infant of 1 year.

Apart from focal increases in Bergmann's cells, the cerebellum was well formed.

The nodule behind the chiasma was formed of glial cells and capillaries (Fig. 4). Most of the glial cells had round or oval nuclei with well-defined nuclear membrane. The nuclei contained powdery particles and two or three larger chromatin nodules. A few cells were smaller and hyperchromatic. The cells were arranged rather loosely except near the blood vessels where they were

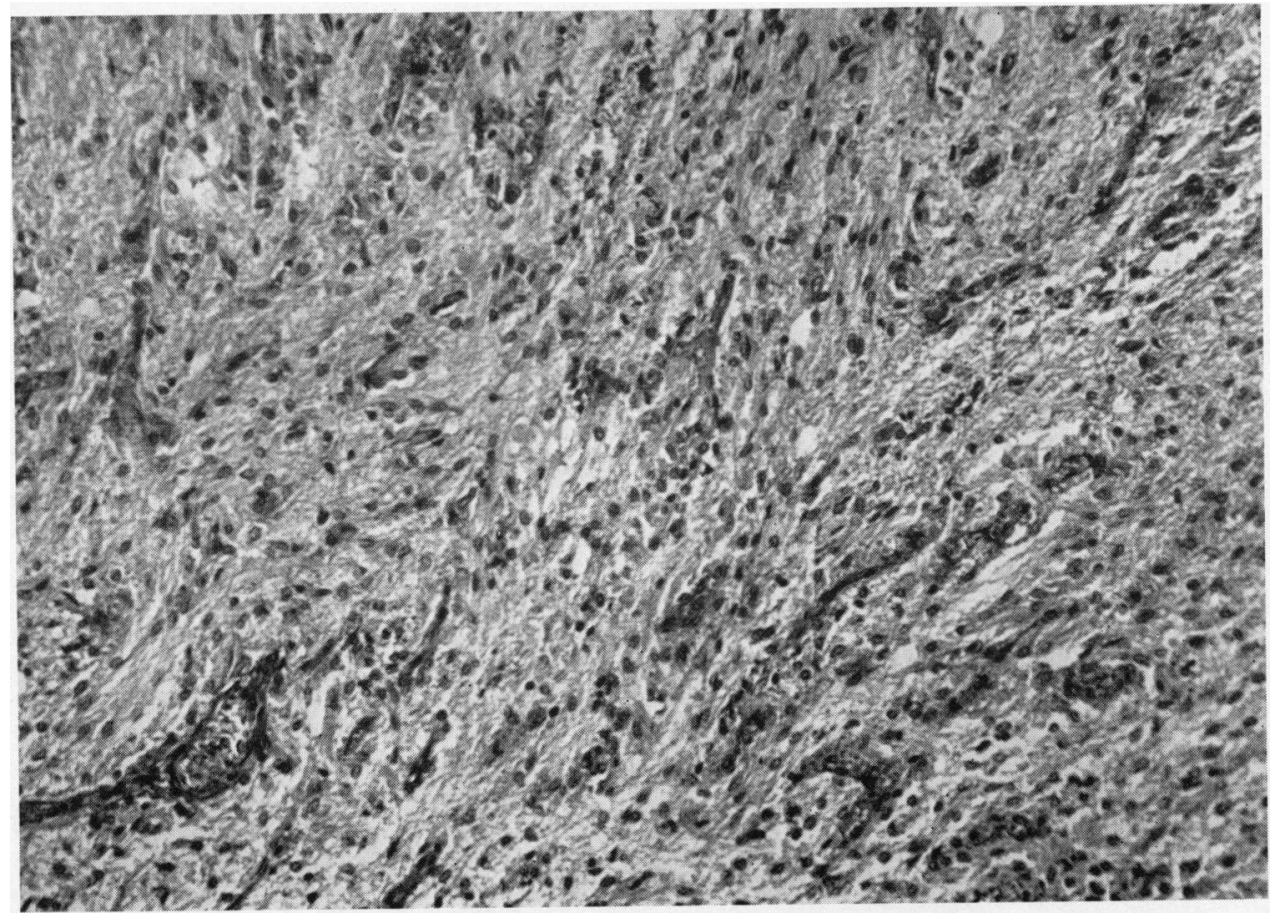

Fig. 4.-Rather haphazard arrangement of glial cells in the infundibuloma had a tendency to more compact arrangement around the vessels. (H. and E. $\times 156$.) 


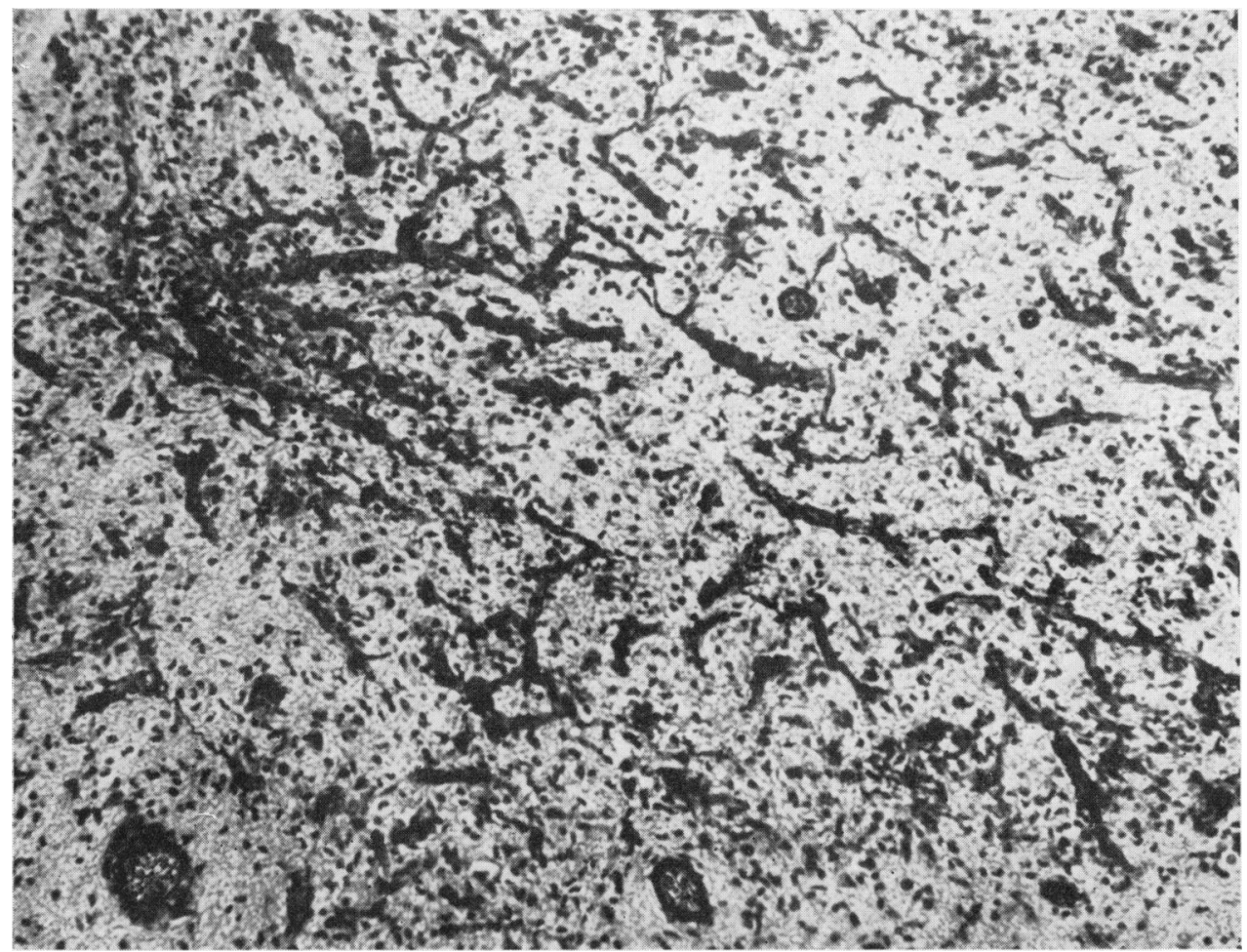

FIG. 5.-Collagenized capillaries, most of them bloodless, and inter-capillary gliosis in the cortical naevus (H.V.G. $\times 162$.

denser. Their fine fibrils formed a delicate open network with occasional microcysts in the H. and E. and H.V.G. preparations. In the Holzer sections there were a few thick sturdy looking angulated fibres. Blood vessels were looped into several coils and contained an excess of reticulin in their walls. This gave them a bizarre glomerular-like appearance. There were neither multinucleated giant cells nor mitotic figures. A few globoid eosinophilic colloidal bodies or droplets were present.

A vascular naevus was found in the grey matter of the parietal lobe in the vicinity of the Rolandic fissure when this was sectioned. Situated in the grey matter bordering a sulcus, it measured approximately $1.5 \mathrm{~mm}$. in length and involved layers I, II and III (molecular, external granular and pyramidal cell layers). It consisted of a network of collagenized capillaries (Fig. 5). Only a few of the capillaries contained red cells. Elastic tissue was not seen in their walls. Glial cells were numerous throughout the area. A dense feltwork of glial fibres was arranged in a racemose fashion around the periphery of the lesion, from which many branches invaded neighbouring grey matter. There were neither saccular nor fusiform dilatations. Calcification was absent.

Numerous calcareous deposits were situated chiefly in the outer half of the pyramids of the kidneys with occasional foci in the medullary rays. Interstitial fibrosis was present around these foci and ischaemic changes were seen in some glomerular tufts. It was often difficult to identify the precise site of the calcified structures because of distortion by fibrosis. Many were large enough to be seen by the naked eye (like grains of black pepper in the von Kossa preparation); for instance, some of the larger deposits were contained within a thin lining of fibrous tissue and it was impossible to say whether they originated within the lumen of a tubule, in its epithelium or in the interstitial tissue. These large deposits compressed surrounding tubules. The smaller deposits were also difficult to place, but some appeared to have formed below the level of the tubular epithelium which they had dislodged towards the lumen. Many smaller deposits appeared to be interstitial.

Glomerular changes were focal and included shrinkage of the capillary tufts with hyperchromasia of nuclei. Fibrous tissue was increased around some Bowman's capsules and the interstitial tissue contained an excess of fibrocytes and round cells. There were no polymorphonuclear cells; there was no calcium-like deposit in the glomeruli or adjacent tissue and blood vessels were normal.

The available sections of the pituitary gland were small when compared with a gland from a child of similar age. Apart from congestion of the sinusoids it appeared normal structurally. Atrophic changes were conspicuous in the thymus and included smallness of lobules with 
poor differentiation between cortex and medulla; Hassall's bodies were calcified and there was a great deal of fibrous stroma and fatty infiltration. There was infiltration of the portal tracts by small round cells. Broncho-pneumonic changes were confirmed in the lungs. Other viscera appeared normal.

\section{Discussion}

The hypercalcaemia and the clinical features of mental deficiency, osteosclerosis and stunting made it reasonably certain that this boy suffered from a severe form of hypercalcaemia of infancy. Failure of the skull to grow adequately after birth and the development of osteosclerosis signified the progressive nature of the disease. Nephrocalcinosis, found in both forms of this disease, was also present and the renal lesions were similar to those described by Dawson, Craig and Perera (1954), Rhaney and Mitchell (1956), and Shanks and MacDonald (1959) Type III lesion. An unusual feature was foci of metastatic calcification in the pulp of a deciduous premolar. Dawson et al. (1954) found similar lesions in a lower deciduous incisor.

Micrencephaly, poor lamination of nerve cells and universal paucity of nerve cells in the grey matter especially in layer III (pyramidal cell layer) were severe enough to account for the mental deficiency in this boy. The paucity of cortical nerve cells could probably in part be due to the excessive number of ectopic nerve cells in the white matter indicating a failure in the normal migration of neuroblasts towards the pallium, either in the later months of pregnancy or early in infancy. Clearly, with the early onset of convulsions and initially raised cerebrospinal fluid protein there was evidence that the disturbance of the nervous system was already present in early infancy. It is also impossible to exclude the possibility of ictal neural damage.

Rhaney and Mitchell (1956) reported medial calcification of the middle cerebral artery within the basal ganglia in a child of 10 months whose brain weight was normal and who suffered from the mild form of the disease. The vessels in this child were free from this abnormality.

The tumour situated between the optic chiasma and hypophysis cerebri had many of the features of an infundibuloma; a condition recently reviewed by Wolman (1959). Its situation invites speculation into the effects it may have had on the child's metabolism and physical state. As indicated in the history, a lesion of the hypothalamus was suspected in life. Diabetes insipidus was not present. Although he was well nourished, he was not excessively fat and his genital organs were quite well developed, there being thus no signs of adiposogenital syndrome. As a matter of interest and by contrast, Kagan (1958) described a large tumour of the third ventricle, regarded as an astrocytoma, in a $5 \frac{1}{2}$-month-old infant in whom the blood calcium was normal and the main features were anorexia and inanition.

The histological character of the vascular naevus did not fit easily into Russell and Rubinstein's (1959) classification of capillary telangiectasis, cavernous angiomas and venous and arteriovenous angiomas. It resembled most a racemose venous naevus composed of small channels. However, a pia-arachnoid component was not demonstrated and the lesion in this child was within the substance of the brain. Corrin (1959) stated that cavernous angiomas were similar in structure to the common cutaneous angiomas and that occasionally they were associated with angiomatous lesions of the skin and other organs. Unfortunately, the skin lesions were not examined histologically.

It was impossible to decide whether the hypercalcaemia was causally related to the naevoid anomalies and the infundibuloma or was a fortuitous complication such as might have arisen from some fault in the early feeding involving calcium and vitamin $\mathrm{D}$ or hypersensitivity to vitamin $\mathrm{D}$; causal factors which have recently been discussed by Bonham Carter, Dent, Fowler and Harper (1955), Morgan, Mitchell, Stowers and Thomson (1956), Fellers and Schwartz (1958), and Forfar et al. (1959). Nevertheless, it could not be ruled out that the more economical explanation of a single cause such as a biochemical defect manifested itself as localized faults of morphogenesis.

\section{Summary}

An epileptic microcephalic idiot boy was stunted and had spastic quadriplegia, capillary-cavernous naevi of the skin and hypercalcaemia and osteosclerosis of the skull. Pathologically, there were micrencephaly, generalized paucity of nerve cells in the grey matter and an excessive number of ectopic nerve cells in the white matter, a gliosed vascular tumour of the left cerebral cortex and an infundibuloma.

Our thanks are due to several colleagues at the Fountain Hospital and the Postgraduate Medical School who supplied information.

\section{REFERENCES}

Bonham Carter, R. E., Dent, C. E., Fowler, D. I. and Harper, C. M (1955). Calcium metabolism in idiopathic hypercalcaemia of infancy with failure to thrive. Arch. Dis. Childh., 30, 399.

Coppoletta, J. M. and Wolbach, S. B. (1933). Body length and organ weights of infants and children. Amer. J. Path., 9, 55. 
Corrin, B. (1959). Three cases of intracranial vascular malformations in infants. J. clin. Path., 12, 412.

Dawson, I. M. P., Craig, W.' S. and Perera, F. J. C. (1954). Idiopathic hypercalcaemia in an infant. Arch. Dis. Childh., 29, 475.

Fanconi, G., Girardet, P., Schlesinger, B., Butler, N., and Black J. (1952). Chronische Hypercalcämie, kombiniert mit Osteosklerose, Hyperazotämie, Minderwuchs und kongenitalen Missbildungen. Helv. paediat. Acta., 7, 314

Fellers, F. X. and Schwartz, R. (1958). Etiology of the severe form of idiopathic hypercalcemia of infancy. New Engl. J. Med., 259,1050

Forfar, J. O., Tompsett, S. L. and Forshall, W. (1959). Biochemical studies in idiopathic hypercalcaemia of infancy. Arch. Dis. Childh., 34, 525 .

Joseph, M. C. and Parrott, D. (1958). Severe infantile hypercalcaemia with special reference to the facies. Ibid., 33, 385 .
Kagan, H. (1958). Anorexia and severe inanition associated with a tumour involving the hypothalamus. Ibid., 33, 257.

Lightwood, R. (1952). Idiopathic hypercalcaemia in infants with failure to thrive. Ibid., 27, 302.

Morgan, H. G., Mitchell, R. G., Stowers, J. M. and Thomson, J. (1956). Metabolic studies on two infants with idiopathic hypercalcaemia. Lancet, 1, 925 .

Rhaney, K. and Mitchell, R. G. (1956). Idiopathic hypercalcaemia of infants. Ibid., 1,1028 .

Russell, D. S. and Rubinstein, L. J. (1959). The Pathology of Tumours of the Nervous System. Arnold, London.

Shanks, R. A. and MacDonald, A. M. (1959). Nephrocalcinosis infantum. Arch. Dis. Childh 34, 115

Stapleton, T. and Evans, I. W. J. (1955). Idiopathic hypercalcaemia in infancy. Helv, paediat. Acta, 10, 149

Wolman, L. (1959). Infundibuloma. J. Path. Bact., 77, 283. 